\title{
Acute Hyponatremia With Seizure and Mental Change After Oral Sodium Picosulfate/Magnesium Citrate Bowel Preparation
}

\author{
Young Sun Cho, Kyung Min Nam, Jang Ho Park, Sang Hwan Byun, Jin Suck Ryu, Hyun Ju Kim \\ Department of Internal Medicine, Wallace Memorial Baptist Hospital, Busan, Korea
}

Sodium picosulfate/magnesium citrate (Picolight Powder), which is used as a bowel preparation for the colon and the rectum, can cause a severe electrolyte imbalance like hyponatremia. When hyponatremia gets severe or occurs rapidly, it can lead to death due to associated complications. We have experienced a case of hyponatremia associated with seizure and loss of consciousness in a 76-year-old woman, who took sodium picosulfate/magnesium citrate as a bowel preparation for colonoscopy. She was taking thiazide and synthroid for the treatment of hypertension and hypothyroidism, respectively, and she had other underlying medical conditions such as a history of seizure and dementia. Following the diagnosis of hyponatremia, we used an intravenous injection of $3 \% \mathrm{NaCl}$ to normalize the sodium level in her serum, and her associated symptoms soon disappeared.

Keywords: Picosulfate sodium; Bowel preparation; Hyponatremia; Seizures; Colonoscopy

\section{INTRODUCTION}

As colonoscopy is becoming more common, a pretreatment solution compatible with the patient's compliance represents an unmet medical need. Four liters of polyethylene glycol (PEG) and sodium phosphate $(\mathrm{NaP})$ have been widely used for pretreatment. In addition, sodium picosulfate and magnesium citrate complex (MC-SP) has been registered as a patent in Korea since 2012. Sodium picosulfate increases bowel peristalsis whereas magnesium citrate acts as an osmosis laxative [1]. In 2005, hyponatremia that caused encephalopathy as a result of taking MC-SP complex was reported in New Zealand [2]. In 2013, one poster presentation reported hyponatremia caused by taking MC-SP complex in Korea. However, no seizures, loss of consciousness or neurologic symp-

Received: July 22, 2014 - Accepted: September 12, 2014

Correspondence to: Hyun Ju Kim, M.D.

Department of Internal Medicine, Wallace Memorial Baptist Hospital,

200 Geumdan-ro, Geumjeong-gu, Busan 609-728, Korea

Tel: +82-51-580-1388, Fax: +82-51-580-7114

E-mail: lotlot98@naver.com

(C) 2014 The Korean Society of Coloproctology

This is an open-access article distributed under the terms of the Creative Commons Attribution NonCommercial License (http://creativecommons.org/licenses/by-nc/3.0) which permits unrestricted non-

commercial use, distribution, and reproduction in any medium, provided the original work is properly cited. toms have been reported in Korea. We report a case of hyponatremia accompanied by seizure and loss of consciousness in a patient who has normal renal function after taking MC-SP for bowel preparation prior to colonoscopy.

\section{CASE REPORT}

A 76-year-old woman came into our Emergency Department due to the loss of consciousness and a seizure. The patient was given an oral prescription of MC-SP complex (Picolight powder, Pharmbio Korea Co., Seoul, Korea) for the colonoscopy. She orally took one pack (10-mg sodium picosulfate, 3.5-g magnesium citrate) with $150 \mathrm{~mL}$ of water. Within 3 hours of her first dose of MC-SP, she suffered diarrhea, and about 11 hours after taking the first medicine, she suffered nausea, vomiting, and then symptoms of decreased energy and seizure accompanied by ocular deviation. Seizures lasted for 2-3 minutes. When she arrived at the Emergency Department, loss of consciousness was evident, but there were no signs of seizure. She had no history of seizures. About 5 years earlier, she had been taking levothyroxine sodium, $0.05 \mathrm{mg}$, (Synthroid, Bukwang Pharm, Seoul, Korea), atorvastatin calcium, $10 \mathrm{mg}$, (Lipinon, Dong-A Pharm, Seoul, Korea), hydrochlorothiazide, $12.5 \mathrm{mg}$ (Dichlozid, Yuhan Pharm, Seoul, Korea), propranolol, 10 mg twice a day (Indenol, Dongkwang Pharm, Seoul, Ko- 
rea), and diazepam, $2 \mathrm{mg}$ (Myungin Diazepam, Myung In Pharm, Seoul, Korea) for hypothyroidism, hyperlipidemia, hypertension and depression, respectively. She had no family history of specific medical diseases. She had no history of alcohol consumption or smoking.

Upon arrival, her blood pressure was 150/90 $\mathrm{mmHg}$, her pulse rate was 83 times per minute, her respiratory rate was 20 times per minute, her body temperature was $36^{\circ} \mathrm{C}$, her blood glucose was $205 \mathrm{mg} / \mathrm{dL}$, and her oxygen saturation level was $92 \%$. The patient looked very sick and vomited continuously. On both sides, the pupil reflex was normal, and no signs of nystagmus manifested. The consciousness of the patient was vague. She couldn't respond to questions and could not even follow verbal instructions. According the Glasgow Coma Scale, her rating was 8 points, which is referred to as semicoma state. Auscultation of the abdomen produced no specific finding. During chest auscultation of both sides of the lower lung, rales were auscultated. Chest radiography showed a shadow increasing on both lower lung field, but there were no specific findings on the electrocardiogram.

Arterial blood gas analysis showed $\mathrm{pH}, 7.532, \mathrm{pCO}_{2}, 27.4 \mathrm{mmHg}$, $\mathrm{pO}_{2}, 56.5 \mathrm{mmHg}, \mathrm{HCO}_{3}, 22.5 \mathrm{mmol} / \mathrm{L}$, base excess, $1.1 \mathrm{mmol} / \mathrm{L}$, and oxygen saturation, $88.5 \%$, indicating that she had acute respiratory alkalosis. In serum biochemical tests, the total calcium level was $8.2 \mathrm{mg} / \mathrm{dL}$ (reference value, $8.8-10.8 \mathrm{mg} / \mathrm{dL}$ ), the ionized calcium level was $0.80 \mathrm{mmol} / \mathrm{L}$ (reference value, $1.0-1.2 \mathrm{mmol} / \mathrm{L}$ ) and phosphate was $2.4 \mathrm{mg} / \mathrm{dL}$ (reference value, $2.4-5.1 \mathrm{mg} / \mathrm{dL}$ ), indicating hypocalcemia and hypophosphatemia. Blood urea nitrogen was $9.6 \mathrm{mg} / \mathrm{dL}$ (reference value, $9-23 \mathrm{mg} / \mathrm{dL}$ ), and the creatinine level was $0.6 \mathrm{mg} / \mathrm{dL}$ (reference value, $0.7-1.3 \mathrm{mg} / \mathrm{dL}$ ), indi- cating no abnormality. The serum sodium level was $112 \mathrm{mEq} / \mathrm{L}$ (reference value, $132-146 \mathrm{mEq} / \mathrm{L}$ ), and the potassium level was 2.4 $\mathrm{mEq} / \mathrm{L}$ (reference value, $3.5-5.0 \mathrm{mEq} / \mathrm{L}$ ), indicating hypokalemia and hyponatremia. The serum osmolality had decreased to 240 $\mathrm{mOsmol} / \mathrm{kg}$ (reference value, $289-308 \mathrm{mOsmol} / \mathrm{kg}$ ), and the urine osmolality was $370 \mathrm{mOsmol} / \mathrm{kg}$ (reference value, $300-900 \mathrm{mOs}$ $\mathrm{mol} / \mathrm{kg}$ ). The fasting blood glucose level was $205 \mathrm{mg} / \mathrm{dL}, \mathrm{Hg} \mathrm{A1C}$ was $7.1 \%$ (reference value, $4.4 \%-6.4 \%$ ), thyroid-stimulating hormone was $0.99 \mu \mathrm{IU} / \mathrm{mL}$ (reference value, $0.55-4.78 \mu \mathrm{IU} / \mathrm{mL}$ ), free thyroxine (fT4) was $1.78 \mathrm{ng} / \mathrm{dL}$ (reference value, $0.89-1.8 \mathrm{ng} / \mathrm{dL}$ ) at $8 \mathrm{AM}$. Cortisol was $46.88 \mu \mathrm{g} / \mathrm{dL}$ (reference value, $4.3-22.4 \mu \mathrm{g} /$ $\mathrm{dL}$ ), and at $8 \mathrm{AM}$. Aadrenocorticotropic hormone (ACTH) was $134.7 \mathrm{pg} / \mathrm{dL}$ (reference value, $5-50 \mathrm{pg} / \mathrm{mL}$ ). The cortisol and ACTH levels had increased.

The brain computed tomography showed no acute brain lesions, such as bleeding (Fig. 1), and the brain magnetic resonance imaging showed no specific lesions. Magnetic resonance angiography showed no specific lesions associated with her current symptoms. She was diagnosed as having hyponatremia accompanied by vomiting and neurological symptoms, such as unconsciousness and seizures, and accompanied by aspiration pneumonia with respiratory alkalosis. To the treat pneumonia, we gave her antibiotics, and to treat the hyponatremia, we gave her an intravenous injection of 3\% saline. We aimed to increase her sodium level to 124 $\mathrm{mEq} / \mathrm{L}$, so we injected $3 \%$ saline at a rate of $20 \mathrm{~mL} / \mathrm{hr}$ for 24 hours, which corresponded to a corrected rate of $0.4 \mathrm{mEq} / \mathrm{L}$. After 24 hours, she got had recovered to a $124-\mathrm{mEq} / \mathrm{L}$ level of serum sodium, and she was in a lethargy state. However, she was not completely oriented and could not questions. Symptoms, including
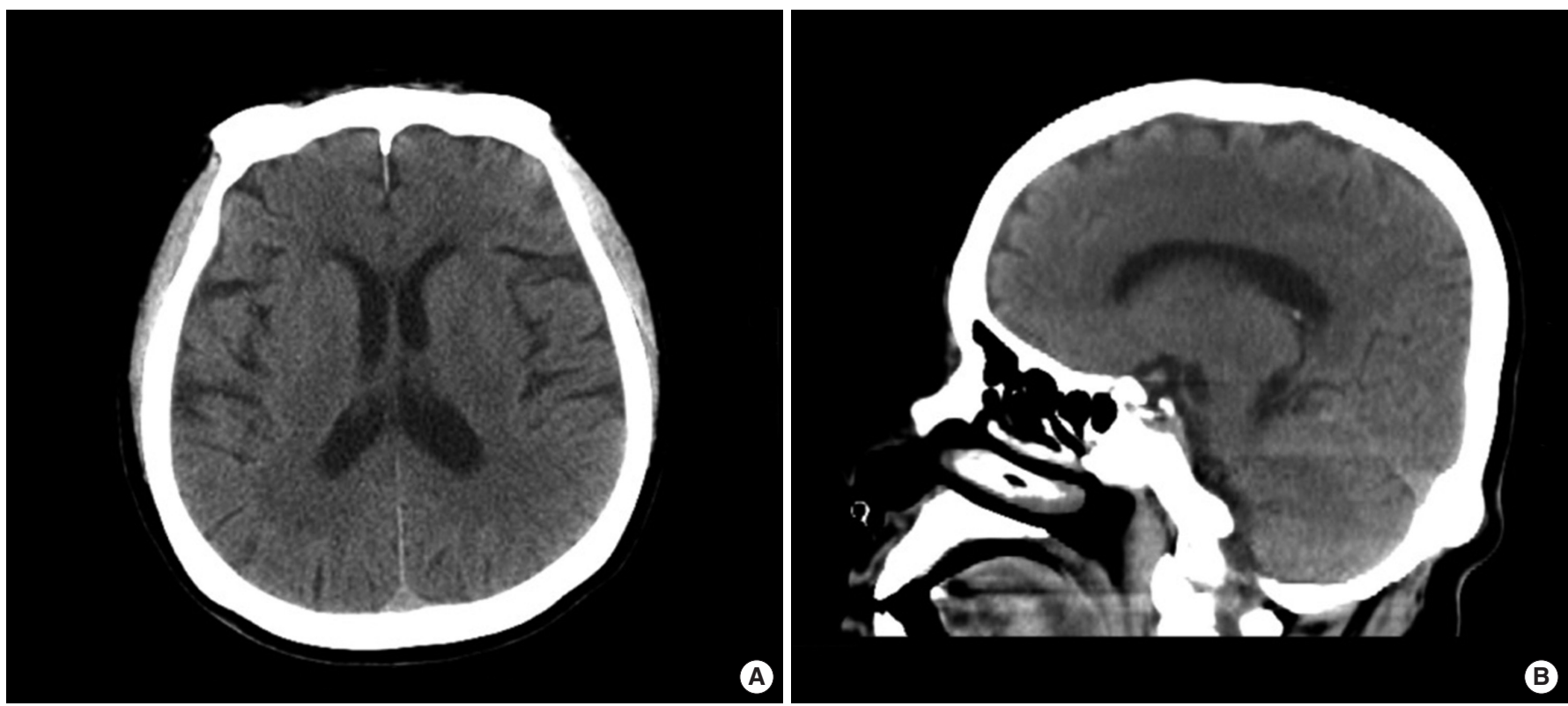

Fig. 1. Brain computed tomography. (A) No evidence of any abnormal density is seen on the pre-enhanced image. (B) No abnormal lesion is noted. 
vomiting and nausea, remained. After 48 hours, she had fully recovered to a 132-mEq/L level of serum sodium, her consciousness was normal, and even her symptoms of vomiting and nausea had disappeared. After that, she showed no neurological symptoms, such as seizures or unconsciousness.

\section{DISCUSSION}

Colonoscopy is a common and widespread test for adults over the age of 50 to screen for colorectal cancer, and its usage is increasing. Doing a proper colonoscopy requires a proper bowel preparation. If the bowel preparation is poorly done, another colonoscopy or another test has to be done, giving an extra burden to the patient and even the physician [3-5]. The most ideal bowel preparation should not only achieve excellent colon cleansing but also minimize the adverse impact on the mucosa and changes in the water and the electrolyte level. The bowel preparation should be drinkable so that patients experience less discomfort [6]. Thus, the patient's compliance has to be acceptable. As a matter of fact, some patients fear a colonoscopy because of the inconvenience of taking the bowel preparation.

Currently the most widely used solutions for bowel preparation are PEG and NaP. In addition, because the MC-SP complex has been approved for clinical use, its benefits and side effects must be evaluated. Sodium picosulfate is commonly used as a bowel preparation solution in Europe and is available in a powder form that can be dissolved in water before use. In 2012, a MC-SP was patented in Korea. Compared with $\mathrm{NaP}$ and PEG, its cleansing ability is similar and it is easy to use [7, 8], so interest in its use in Korea is growing. The patient compliance when using the MC-SP complex has been reported to be better than those of PEG and $\mathrm{NaP}$, and its the bowel cleaning effect has been reported to be comparable [8]. One flaw is that the MC-SP complex causes inflammation in the mucous membrane, although the patient's preference for this complex is higher than it is for either PEG or $\mathrm{NaP}$ [9-11]. According to studies that investigated hyponatremia that occurred when elderly patients over the age of 65 took PEG and sodium picosulfate, the incidence of hyponatremia was higher when the patients took sodium picosulfate, but no significant differences in the neurological symptoms and the lengths of hospital stay were observed [12]. Because taking picosulfate can cause side effects like severe dehydration or electrolyte disturbances, patients should be instructed to take it with enough water. In addition, care should be exercised when using picosulfate in patients with impaired renal function, heart failure, and with inflammatory bowel disease [13].

Looking at the cases reported in other countries, hyponatremia after taking MC-SP complex was associated with taking medicine for hypothyroidism, receiving treatment for hypertension, and being elderly. Underlying diseases and advanced age represent risk factors [3]. A poster presentation at the 2013 Korean Association of Internal Medicine Meeting reported one case of hypona- tremia associated with MC-SP. The patient was old and had taken medicines for hyperlipidemia and hypertension.

Hyponatremia is defined as a serum sodium level less than 135 $\mathrm{mEq} / \mathrm{L}$. Symptoms do not normally occur unless the serum sodium level is below $120 \mathrm{mEq} / \mathrm{L}$. However, symptoms might occur at a level above that level when the rate of decrease of the serum sodium level is higher than usual. The symptoms range from milder ones, such as loss of appetite, nausea, and vomiting, to more severe ones, such as seizure, lethargy, coma, and even death. If the patient has neurological symptoms or a serum sodium concentration less than $110 \mathrm{mEq} / \mathrm{L}$, that patient requires emergency treatment. If the plasma volume is normal, the cause of hyponatremia could be attributed to hypothyroidism, adrenal insufficiency, inappropriate secretion of antidiuretic hormone syndrome, and drugs, and if the plasma volume is high, chronic kidney disease, heart failure, liver failure, and nephrotic syndrome may be the cause. When the patient has a small plasma volume, a lack of water due to dehydration, diarrhea, and vomiting, or a deficiency in renal sodium reabsorption may be the problem. Hyponatremia symptoms are treated with a hypersaline solution when the plasma volume is large or when it is normal with concentrated urine. In the case of a patient having diluted urine, water intake needs to be restricted. If the symptoms become severe, a hypersaline injection is needed.

The case we report here is an elderly patient, who first suffered nausea and vomiting, after taking MC-SP complex for bowel preparation. Eventually, her symptoms manifested a severe hyponatremia accompanied by the loss of consciousness and seizures. She had been taking the drug thiazide. We reasoned that the hyponatremia was attributable to excess dehydration caused by vomiting and diarrhea and that the thiazide diuretics, which decrease urine dilution, made hyponatremia even more severe, to the extent that it was accompanied by loss of consciousness. For patients having risk factors such as aging and underlying medical conditions such as taking diuretics medicine, we highly recommend that they be informed of the enhanced likeliness of having an electrolyte imbalance, which could be accompanied by other complication. In addition, serum electrolytes should be checked if behavioral abnormalities, such as altered consciousness, are apparent at the time of colonoscopy.

\section{CONFLICT OF INTEREST}

No potential conflict of interest relevant to this article was reported.

\section{REFERENCES}

1. Jauch R, Hankwitz R, Beschke K, Pelzer H. Bis-(p-hydroxyphenyl)pyridyl-2-methane: the common laxative principle of Bisacodyl and sodium picosulfate. Arzneimittelforschung 1975;25:1796-800.

2. Frizelle FA, Colls BM. Hyponatremia and seizures after bowel 
preparation: report of three cases. Dis Colon Rectum 2005;48: 393-6.

3. Forde H, O'Shea T, Davenport C, Smith D. Acute symptomatic hyponatremia following sodium picosulfate/magnesium citrate as bowel preparation for colonoscopy: a case series. Case Rep Clin Med 2014;3:101-4.

4. Harewood GC, Sharma VK, de Garmo P. Impact of colonoscopy preparation quality on detection of suspected colonic neoplasia. Gastrointest Endosc 2003;58:76-9.

5. Froehlich F, Wietlisbach V, Gonvers JJ, Burnand B, Vader JP. Impact of colonic cleansing on quality and diagnostic yield of colonoscopy: the European Panel of Appropriateness of Gastrointestinal Endoscopy European multicenter study. Gastrointest Endosc 2005;61:378-84.

6. Rex DK, Imperiale TF, Latinovich DR, Bratcher LL. Impact of bowel preparation on efficiency and cost of colonoscopy. Am J Gastroenterol 2002;97:1696-700.

7. Wexner SD, Beck DE, Baron TH, Fanelli RD, Hyman N, Shen B, et al. A consensus document on bowel preparation before colonoscopy: prepared by a task force from the American Society of Colon and Rectal Surgeons (ASCRS), the American Society for Gastrointestinal Endoscopy (ASGE), and the Society of American Gastrointestinal and Endoscopic Surgeons (SAGES). Gastrointest
Endosc 2006;63:894-909.

8. Barkun A, Chiba N, Enns R, Marcon M, Natsheh S, Pham C, et al. Commonly used preparations for colonoscopy: efficacy, tolerability, and safety: a Canadian Association of Gastroenterology position paper. Can J Gastroenterol 2006;20:699-710.

9. Katz PO, Rex DK, Epstein M, Grandhi NK, Vanner S, Hookey LC, et al. A dual-action, low-volume bowel cleanser administered the day before colonoscopy: results from the SEE CLEAR II study. Am J Gastroenterol 2013;108:401-9.

10. Tan JJ, Tjandra JJ. Which is the optimal bowel preparation for colonoscopy: a meta-analysis. Colorectal Dis 2006;8:247-58.

11. Worthington J, Thyssen M, Chapman G, Chapman R, Geraint M. A randomised controlled trial of a new 2 litre polyethylene glycol solution versus sodium picosulphate + magnesium citrate solution for bowel cleansing prior to colonoscopy. Curr Med Res Opin 2008;24:481-8.

12. Lawrance IC, Willert RP, Murray K. Bowel cleansing for colonoscopy: prospective randomized assessment of efficacy and of induced mucosal abnormality with three preparation agents. Endoscopy 2011;43:412-8.

13. Weir MA, Fleet JL, Vinden C, Shariff SZ, Liu K, Song H, et al. Hyponatremia and sodium picosulfate bowel preparations in older adults. Am J Gastroenterol 2014;109:686-94. 